\title{
The Myers-Briggs Type Indicator (MBTI) and Promotion at Work
}

\author{
Adrian Furnham ${ }^{1,2}$, John Crump ${ }^{1}$ \\ ${ }^{1}$ Research Department of Clinical, Educational and Health Psychology, University College London, London, UK \\ ${ }^{2}$ Norwegian Business School (BI), Olso, Norway \\ Email: a.furnham@ucl.ac.uk
}

Received 17 August 2015; accepted 18 September 2015; published 21 September 2015

Copyright $(2015$ by authors and Scientific Research Publishing Inc.

This work is licensed under the Creative Commons Attribution International License (CC BY).

http://creativecommons.org/licenses/by/4.0/

(c) (i) Open Access

\begin{abstract}
Over 6000 adult managers attending an assessment centre completed the MBTI and also specified in detail how long it had been before they were promoted to a managerial role, and also, where appropriate, to a senior managerial role. Correlational analyses showed shorter times to promotion were associated with being Extraverted and a Sensing Type. Regressions showed that Feeling types took longer to be promoted to managerial roles, and that Perceiving types took longer to be promoted to senior positions. Implications for the selection and management of people were considered.
\end{abstract}

\section{Keywords}

Promotion, MBTI, Sex, Age

\section{Introduction}

This study looks at MBTI traits that relate to promotion at work. It has "years to promotion" as the criterion variable and MBTI as the independent or predictor variables. It has long been established that personality correlates with many performance indicators at work, but surprisingly few papers have examined the personality and ability factors associated with promotion, preferring to study such issues as gender differences (Almer, Lightbody, \& Single, 2012).

There have not been many studies on speed of, or factors related to promotion at work. There have, however been a number of studies on personality correlates of people at different levels in an organisation the implication being those personality traits in some way "assisted" in their promotion. Furnham, Crump, \& Chamorro-Premuzic (2007) examined individual difference factors related to management level: intelligence, personality traits and personality disorders. With respect to the dark side traits as measured by the Hogan Developmental Survey 
(Hogan \& Hogan, 1997) senior managers tended to be less diligent and dutiful than junior managers.

Moutafi, Furnham, \& Crump (2007) looked at sex, age, Big Five, and personality test correlates of managerial level in 900 managers. The more senior the manager was the more he/she was likely to be achievement striving, dutiful, competent, orderly, assertive, active and gregarious and the less likely they were to be anxious, depression prone, self-conscious and vulnerable. In another study of over 5000 managers, Furnham \& Crump (2015) using the NEO-PI-R and Firo B, found that senior managers tended to be high on Extraversion and Expressed Control and low on Neuroticism and Wanted Inclusion.

In a more recent study Palaiou \& Furnham (2014) compared the Big Five Personality facet scores of 138 CEO's compared to senior managers. The former were significantly less Neurotic, and had higher Extraversion, Agreeableness and Conscientiousness on both Domain and Facet levels. The results were then investigated in five work sectors and in all CEOs that were less Neurotic and more Conscientious with Cohen's $\mathrm{d}$ between 0.30 and 0.85 .

Perhaps the most relevant study to this was that of Furnham, Crump, \& Ritchie (2013) which looked at 6000 adult managers attending an assessment centre where they specified in detail how long it had been before they were promoted to a managerial role, and also, where appropriated to a senior managerial role. Correlational analyses showed shorter times to promotion were associated with low Neuroticism, Extroversion, high Conscientiousness, and high Intelligence, as well as being high on Bold and Colourful, but low on Cautious, Reserved and Leisurely "dark side" traits. This study used data similar to that of Furnham et al. (2013) but used the Myers Briggs Type Indicator (MBTI) as the personality test used as the independent variable.

\subsection{The MBTI}

Researchers have also looked, though to a much lesser extent, at the relationships between job performance and the four bipolar personality dimensions derived by the Myers Briggs Type Indicator (MBTI) (Myers \& McCauley, 1985), a test based on Jung's theory of personality dimensions. The test however has not been without criticism of its theoretical heritage or psychometric properties (Furnham, 2008).

Various papers have examined the MBTI in the workplace (Berr, Church, \& Waclawski, 2000; Creasy \& Anantatnula, 2013; Luse, McElroy, Townsend, \& DeMarie, 2013). The Extraversion-Introversion dimension has been found to correlate modestly with self-reported income (Rice \& Lindecamp, 1989). Extraversion-introversion has also been indirectly linked to job performance through job satisfaction, with extraverts being more satisfied than introverts (Rahim, 1981). With respect to the sensing-intuition dimension sending individuals have been found to perform better at innovative projects than intuitive individuals (Henderson \& Nutt, 1980). It has also been proposed, however, that culture could be a moderating factor in the relationship between job performance and Extraversion-Introversion, as well as Sensing-Intuition (Furnham \& Springfield, 1993).

The Judging-Perceiving and the Thinking-Feeling dimensions have also been modestly linked to job performance (Nordvik \& Brovold, 1998). Judging-perceiving has further been indirectly linked to job performance, through job satisfaction, with judging types being more satisfied than perceiving types, irrespective of their occupation (Rahim, 1981). The Thinking-Feeling dimension has also been found to be linked to success in small retailers (Rice \& Lindecamp, 1989), and it has been suggested that feeling individuals should perform better at jobs requiring innovation com-pared with thinking individuals (Henderson \& Nutt, 1980).

\subsection{This Study}

This study looked at MBTI traits, as well as demographic correlates, of years to promotion. It seems reasonable to expect that in all organisations people with particular attributes are selected for their ability to lead/manage/ supervise others. Based on the literature on the MBTI and leadership success it was predicted that speed of promotion would be positively linked to Extraversion, Intuition, Thinking and Judgemental style.

\section{Method}

\subsection{Participants}

There were a total of 7083 participants of whom 5568 were males and 1515 females. Their mean age was 40.07 years $(\mathrm{SD}=7.76)$. They were employed in mainly large British organisations in the public and private sector, 
including banking and finance, pharmaceutical, engineering and law. They ranged from their late $30 \mathrm{~s}$ to their middle $50 \mathrm{~s}$ (mean age $=40.3$ years). Of these 4365 (3563 males) had been promoted to manager and 3119 (2618 males) promoted to senior manager.

\subsection{Measures}

\subsubsection{Years to Promotion}

Participants were asked to specify, in years, how long it had taken before they were promoted to a managerial position as well as a senior management position. Because people came from different companies and different sections an effort was made to clarify what was meant by different roles: i.e. technical expert, supervisor, manager, senior manager so that all participants could understand what was meant. They found little difficulty in the task. On average it took 7 years to manager and just under 12 years to senior manager.

\subsubsection{Myers-Briggs Type Indicator-Form G}

(MBTI: Myers \& Mc Caulley, 1985). The Myers-Briggs indicator is a Jungian-based inventory that uses a paper-and-pencil self-report format. It is composed of 94 forced-choice items that yield scores on each of the eight factors as well as the famous four dimensions: Introversion-Extraversion, Sensation-Intuition, Thinking-Feeling and Judging-Perceiving. Respondents are classified into one of 16 personality types based on the largest score obtained for each bipolar scale (e.g. a person scoring higher on Introversion than Extraversion, Intuition than Sensation, Feeling than Thinking and Judging than Perceiving would be classified as an Introverted Intuitive Feeling Judging). The test provides linear scores on each dimension which are usually discussed in terms of types based on cut-off scores. Thus the Extraversion-Introversion dimension has a normal distribution with high scores being considered Extraverted and low Introverted. The Myers-Briggs Type Indicator has been the focus of extensive research and substantial evidence has accumulated suggesting the inventory has satisfactory concurrent and predictive validity and reliability (Furnham \& Stringfield, 1993).

\subsection{Procedure}

Participants were required to attend a middle management assessment centre where they completed the questionnaires. The assessment was aimed at determining the suitability of each manager for promotion. Each manager was given feedback on the results, including how he/she related to the test norms as well as his/her colleagues. Because data collection was done at an assessment centre it is possible that scores may be distorted through impression management processes. This could lead to defensiveness on the part of participants with truncated scores and reduced variance. Examination of both sets of scores suggests this may have occurred but there remained considerable variations in each dimension of each measure.

The data analysis involved first correlations and then multiple regressions.

\section{Results}

\subsection{Correlations}

Table 1 shows the correlations between all the measures. The columns in bold indicate the relationship between the major variables of interest. A negative correlation means a faster rate of promotion. Two things are noticeable: first correlations are low, particularly for promotion to senior manager; second that Extraverts (E) and Sensing types (SN) do better. These correlations were repeated for the four scales and the only significant correlation was between $\mathrm{SN}$ and years to promotion for senior managers: $\mathrm{SN} r=0.04, p<0.01$

\subsection{Regressions}

A series of regressions were run first with years to manager as the criterion. Table 2 shows two significant predictors indicating that older participants with lower Feeling scores got promoted more quickly. When this was repeated on the higher order scales only age was significant. Table 3 shows there were two significant predictors of years to senior management: older participants and those with lower Perceiving schools got promoted to senior positions more quickly. The higher order analysis was significant $(\mathrm{F}(6,1796)=47.32, p<0.001$; AdjR2 $=0.13$ ) showed two significant predictors: Age (Beta $=-0.35, t=15.81, p<0.001$ and SN (Beta $=0.05, t=2.00$, $p<0.05)$. 
Table 1. Correlations between all variables.

\begin{tabular}{|c|c|c|c|c|c|c|c|c|c|c|c|c|c|}
\hline & Mean & SD & G & Age & YM & YSM & $\mathrm{E}$ & I & S & $\mathrm{N}$ & $\mathrm{T}$ & $\mathrm{F}$ & $\mathrm{J}$ \\
\hline Gender (G) & 1.44 & 0.43 & & & & & & & & & & & \\
\hline Age & 40.19 & 7.76 & 0.01 & & & & & & & & & & \\
\hline Years to Manager (YM) & 7.00 & 4.64 & -0.09 & -0.27 & & & & & & & & & \\
\hline $\begin{array}{l}\text { Years to Senior } \\
\text { Manager (YSM) }\end{array}$ & 11.69 & 5.82 & -0.11 & 0.33 & 0.33 & & & & & & & & \\
\hline Extraversion (E) & 16.08 & 5.94 & 0.08 & 0.12 & -0.08 & -0.02 & & & & & & & \\
\hline Introversion (I) & 10.17 & 6.27 & -0.07 & -0.09 & 0.09 & 0.01 & -0.88 & & & & & & \\
\hline Sensing (S) & 11.94 & 7.51 & -0.02 & -0.00 & 0.09 & 0.03 & -0.13 & 0.17 & & & & & \\
\hline Intuition $(\mathrm{N})$ & 12.90 & 5.90 & 0.03 & 0.01 & -0.08 & -0.02 & 0.14 & -0.14 & -0.90 & & & & \\
\hline Thinking (T) & 17.32 & 6.61 & -0.20 & 0.02 & -0.01 & 0.00 & -0.04 & 0.05 & 0.16 & -0.14 & & & \\
\hline Feeling (F) & 4.78 & 3.93 & 0.16 & 0.01 & 0.04 & 0.02 & 0.04 & -0.02 & -0.14 & 0.16 & -0.82 & & \\
\hline Judging (J) & 16.79 & 6.47 & 0.01 & -0.04 & 0.04 & 0.02 & -0.09 & 0.12 & 0.42 & -0.40 & 0.20 & -0.20 & \\
\hline Perceiving (P) & 10.95 & 6.51 & 0.01 & 0.02 & -0.03 & 0.01 & 0.10 & -0.09 & -0.41 & 0.43 & -0.17 & 0.20 & -0.92 \\
\hline
\end{tabular}

Table 2. Years to manager regressions.

\begin{tabular}{cccc}
\hline & Beta & $t$ & Sig \\
\hline Gender & -0.04 & -1.69 & 0.09 \\
Age & 0.23 & -14.49 & 0.00 \\
Extraversion & 0.01 & 0.21 & 0.85 \\
Introversion & 0.07 & 1.44 & 0.15 \\
Sensing & 0.04 & 0.69 & 0.48 \\
Intuitive & -0.03 & -0.68 & 0.49 \\
Thinking & 0.07 & 1.68 & 0.09 \\
Feeling & 0.12 & 2.98 & 0.00 \\
Judging & -0.03 & -0.52 & 0.61 \\
Perceiving & -0.01 & -0.18 & 0.86
\end{tabular}

$\mathrm{F}(10,1808)=26.01, p<0.001, \operatorname{Adj}^{2}=0.12$.

Table 3. Years to senior manager regressions.

\begin{tabular}{ccccc}
\hline & Beta & $t$ & Sig \\
Gender & -0.06 & -2.39 & 0.01 \\
Age & -0.35 & -15.32 & 0.00 \\
Extraversion & -0.03 & -0.74 & 0.45 \\
Introversion & -0.04 & -1.04 & 0.30 \\
Sensing & 0.03 & 0.46 & 0.64 \\
Intuitive & -0.03 & -0.47 & 0.64 \\
Thinking & 0.04 & 0.95 & 0.34 \\
Feeling & 0.06 & 1.45 & 0.15 \\
Judging & 0.10 & 1.73 & 0.08 \\
Perceiving & 0.13 & 2.30 & 0.02 \\
\hline
\end{tabular}

$F(10,1716)=27.47, p<0.001, \operatorname{AdjR}^{2}=0.13$.

The regression were repeated with two different time variables: first, Time to Manager plus Time to Senior Manager; second Time to Senior Manager minus Time to Manager. The former was significant $(F(6,1796)=$ 
43.71, $p<0.001, \operatorname{AdjR}^{2}=0.20$ ). It indicated that younger females who were Feeling types took longest to be promoted.

\section{Discussion}

In this study we were interested primarily in personality styles of time to promotion. The correlational results suggested that the Extravert, Intuitive, Thinking, Perceiving type (ENTP) profile was linked with the speed of promotion to manager. These types were described by Myers (2000), thus: "Quick, ingenious, stimulating, alert and outspoken. Resourceful in solving new and challenging problems. Adept at generating conceptual possibilities and then analysing them strategically. Good at reading other people” (p. 13). However the pattern was much weaker for the variable promotion to senior manager.

The results of the regressions were more important. The first regression showed that the only type related to promotion was Feeling: those with high scores were slow in being promoted. This was probably because the Feeling dimension was correlated both with Neuroticism and Agreeableness, both traits linked to lack of managerial success (Furnham, 2008). This might be because Feeling types might be particularly prone to inter-personal stress and more interested in group dynamics and happiness than strategy

With regard to senior management, the only trait that proved significant in the regression was Perceiving. People who scored highly on this dimension were described as spontaneous, flexible and liking things loose and open to change. Whilst their adaptability and resourcefulness might be thought to be advantageous in senior management positions, the systematic, methodical, organised and planed lives of Judging types seemed much more useful at senior management levels.

Overall it should be noted that the personality variables accounted for only a small percentage of the variance. Inevitably age, supposedly associated with experience and knowledge was the best predictor of promotion. Also it should be noted that the results from the higher order analysis suggested that it was the S-N dimension that was the best predictor of promotability to both manager and senior manager. Those who were more Intuitive did better which was to be expected given that those with an Intuitive preference were described as focused on patterns and meanings in data, able to move quickly to conclusions and having a need to clarify ideas before putting them into practice.

The sample in this study was both a source of strength and weakness because it was heterogeneous in terms of organisation. If we used one organisation, we could have been much clearer about the exact definitions of management but that would have restricted the size of the sample and the generalisability of the results across different organisations. Inevitably, there were probably differences in the precise understanding of the term manager and senior manager. Further we had no indication of the participants' education and training, or varied work experience which might have contributed significantly to their promotion. We also did not know whether they were effective as managers. In future studies in this neglected area it would be advantageous to gather and analyse the above information in conjunction with the personality and ability factors used in this study.

\section{Conclusion}

In conclusion, the study showed as expected that certain personality types were more likely to be promoted than others. This study showed, as expected that Extraverts with their social self-confidence and sociability; and Intuitive types with their "big picture" perspective were more likely to be promoted. Similarly, Feeling types who perhaps based their decision making too much on emotional, rather than rational, factors were slower to be promoted. However the personality factors accounted for little of the variance in promotability suggesting other things might play a much more important role.

\section{References}

Almer, E., Lightbody, M., \& Single, L. (2012). Successful Promotion or Segregation from Partnership. Accounting Forum, 36, 122-133. http://dx.doi.org/10.1016/j.accfor.2011.06.002

Berr, S., Church, A., \& Waclawski, J. (2000). The Right Relationship Is Everything: Linking Personality Preferences to Managerial Behaviours. Human Resource Development Quarterly, 1, 133-143. http://dx.doi.org/10.1002/1532-1096(200022)11:2<133::AID-HRDQ4>3.0.CO;2-T

Creasy, T., \& Anantatmula, V. (2013). From Every Direction-How Personality Traits and Dimensions of Project Managers Can Conceptually Affect Project Success. Project Management Journal, 44, 36-51. http://dx.doi.org/10.1002/pmj.21372 
Furnham, A. (2008). Personality and Intelligence at Work. London: Routledge. http://dx.doi.org/10.4324/9780203938911

Furnham, A., \& Crump, J. (2015). Personality and Management Levels. Psychology, 6, 549-559. http://dx.doi.org/10.4236/psych.2015.65053

Furnham, A., \& Stringfield, P. (1993). Personality and Work Performance. Personality and Individual Differences, 14, 145153. http://dx.doi.org/10.1016/0191-8869(93)90184-5

Furnham, A., Crump, J., \& Chamorro-Premuzic, T. (2007). Managerial Level, Personality and Intelligence. Journal of Managerial Psychology, 22, 805-818. http://dx.doi.org/10.1108/02683940710837732

Furnham, A., Crump J., \& Ritchie, W. (2013). What It Takes: Ability, Demographic, Bright and Dark Side Trait Correlates of Years to Promotion. Personality and Individual Differences, 55, 952-956. http://dx.doi.org/10.1016/j.paid.2013.07.469

Henderson, J., \& Nutt, P. (1980). The Influence of Decision Style on Decision Making Behaviour. Management Science, 26, 371-386. http://dx.doi.org/10.1287/mnsc.26.4.371

Hogan, R., \& Hogan, J. (1997). Hogan Development Survey Manual. Tulsa, OK: HAS.

Luse, A., McElroy, J., Townsend, A., \& DeMarie, S. (2013). Personality and Cognitive Style as Predictors of Preference for Working in Virtual Teams. Computers in Human Behaviour, 29, 1825-1832. http://dx.doi.org/10.1016/j.chb.2013.02.007

Moutafi, J., Furnham, A., \& Crump, J. (2007). Is Management Level Related to Personality? British Journal of Management, 18, 272-280. http://dx.doi.org/10.1111/j.1467-8551.2007.00511.x

Myers, I. (2000). Introduction to Type. Oxford: OPP.

Myers, I., \& McCaulley, M. (1985). Manual: A Guide to the Development and Use of the Myers-Briggs Type Indicator. Palo Alto, CA: Consulting Psychologists.

Nordvik, H., \& Brovold, H. (1998). Personality Traits in Leadership Tasks. Scandinavian Journal of Psychology, 39, 61-64. http://dx.doi.org/10.1111/1467-9450.00057

Palaiou, K., \& Furnham, A. (2014). Are Bosses Unique? Personality Facet Differences between CEOs and Staff in Five Work Sectors. Consulting Psychology Journal: Practice and Research, 66, 173-196. http://dx.doi.org/10.1037/cpb0000010

Rahim, A. (1981). Job Satisfaction as a Function of Personality Job Congruence. Psychological Reports, 49, 496-498. http://dx.doi.org/10.2466/pr0.1981.49.2.496

Rice Jr., G. H., \& Lindecamp, D. P. (1989). Personality Types and Business Success of Small Retailers. Journal of Occupational Psychology, 62, 177-182. http://dx.doi.org/10.1111/j.2044-8325.1989.tb00488.x 